\title{
Reading English as a foreign language: The interplay of abilities and strategies
}

\author{
Abdulkhaleq Abdulhadi Al-Qahtani \\ Department of English, Faculty of Languages and Translation, King Khalid University, PO Box 9100, Abha, \\ Saudi Arabia
}

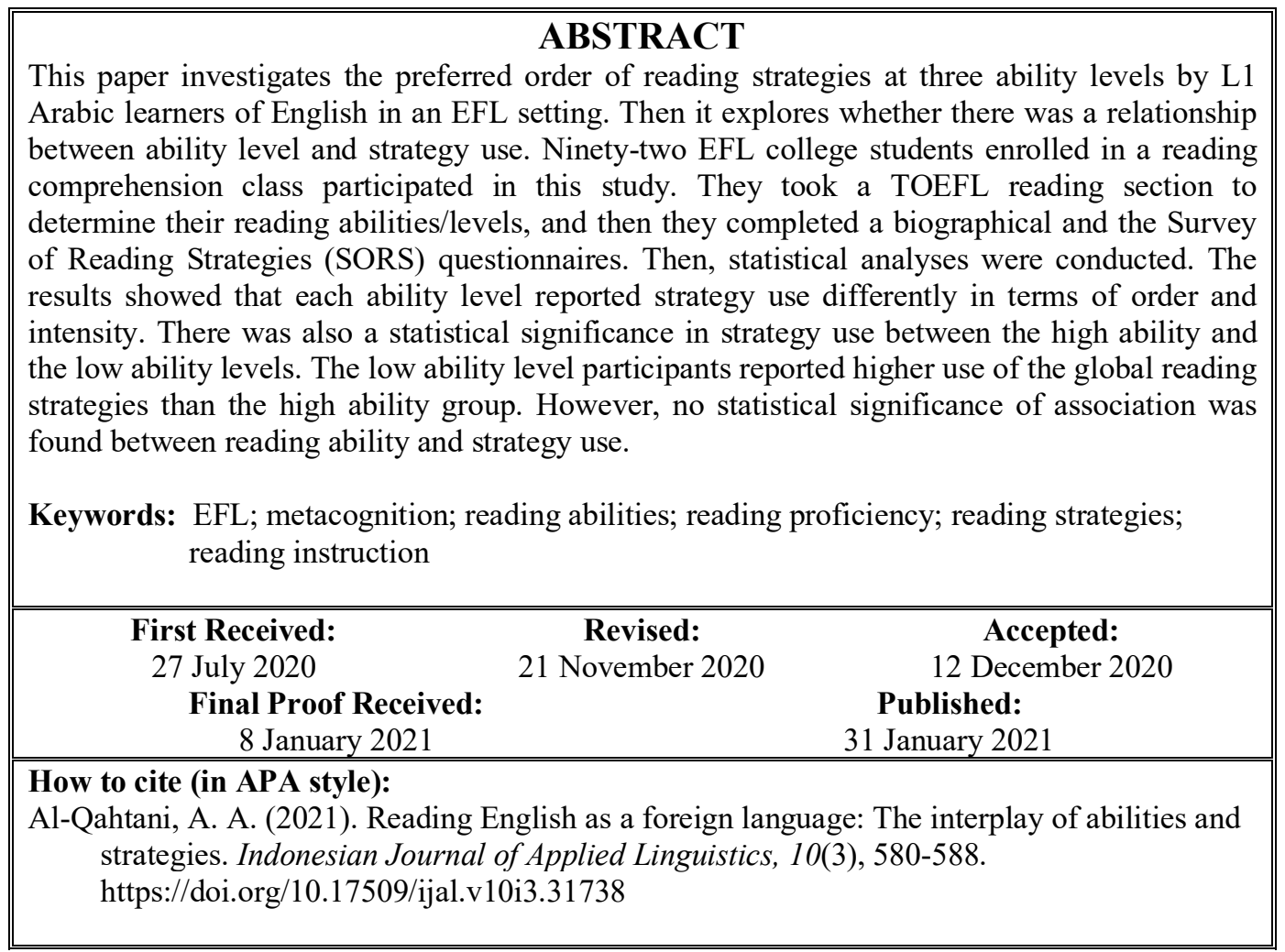

\section{INTRODUCTION}

Reading in a second/foreign language is the most central skill that second language literacy evolves around. The teaching and learning of reading had been abreast applied linguistics research agenda in the twentieth century (e.g., Baker \& Brown, 1984; Block, 1986; Carrell, 1985, 1989, 1998; Clarke, 1979; Goodman, 1967; Gough, 1972; Stanovich, 1980). It seems that the endeavor will keep trending in the future as well. Applied linguists, in particular, have developed research agenda that caters to reading education to help facilitate reading, analyze related factors, and devise ways to enhance the reading enterprise at large.

Reading strategies and their role in reading at various ability levels in a second language have gained momentum in the past two decades. Several research studies were directed to identifying reading strategies, their taxonomies, and issues affecting their use (e.g., He, 2008; Lee-Thompson, 2008). Some other research projects were geared toward devising tools to measure reading strategies and their relation to reading comprehension. One, if not the most, influential measurement tool for reading strategies is the Survey of Reading Strategies (SORS) developed by Mokhtari and Sheorey (2002). The tool was proven to be a valid and reliable means to measure the use of reading strategies. It classifies reading strategies into three types: Global Strategies, Problem-solving Strategies, and Support Strategies. Thus, tens of studies used this instrument for gauging strategy use, their order, and its relation to reading proficiency.

Some of these studies that used the SORS yielded inconsistent findings even though they dealt with similar questions in comparable situations. This 
intrigued researchers to find out possible explanations. One possible reason that has been pointed out is the role of learners' L1 literacy experiences and features. It seems that L1 features have a say in how L2 readers approach the task of reading and how they use reading strategies (Abbott, 2006; Bang \& Zaho, 2007). Thus, research studies were conducted on specific EFL learners from various L1 backgrounds like Arabic, Chines, Korean, Malay, Persian, Turkish, etc. For example, when rank-ordering strategies recognized by L1 Persian college-student learners, Tavakoli (2014) found that learners used to support strategies at a moderate rate first, followed by global strategies problem-solving strategies the least. Madhumathi and Ghosh (2012), however, studied Hindi speaking college students and found the order to be problemsolving strategies first followed by global and then support strategies. Pammu et al. (2014) studied the order for learners in college from Bahasa Indonesia and found the order to be different from the previous two studies; the order was high use of problemsolving, moderate use of support, and low level of global reading strategies. In sum, the literature's inconsistency could be ascribed at least in part to L1 influence.

The proficiency level was another factor that researchers thought would affect the use of reading strategies (Phakiti, 2003; Sheorey \& Mokhtari, 2001; Zhou \& Zhao, 2014). The students' reading ability goes higher, so is the strategy use. One can argue both ways, either good strategy usage increases reading proficiency or higher proficient readers use more strategies as a byproduct. Either way, the problem-solving and the global strategies are used more frequently among high ability readers who become freer from text-related problems such as parsing and word recognition, difficulties that are more associated with lower ability reading levels.

The ensuing study ventures to add to the ongoing discussions in the previous research with EFL Arabic learners. It will investigate certain aspects of reading strategies for this particular L1 group: the rank order at three ability levels and the relationship to reading proficiency. The study seeks to answer the following questions:

1. How do EFL learners use reading strategies? In what order?

2. Does reading ability level affect the order of strategy use? In other words, would high ability readers choose a different order of strategies from the lower two levels? Further, is there statistical significance between the high ability and the low ability groups in terms of strategy use?

3. Does the use of reading strategies correlate with perceived English proficiency? Is there a relationship between reading ability as manifested in
TOEFL scores and reading strategies? Does perceived reading proficiency correlate with reading ability?

\section{METHOD \\ Participants}

Ninety-two EFL students participated from a major university in Saudi Arabia. The participants were second-year students taking a third-semester reading-comprehension course. To acquire many participants, the data collection went on for three consecutive semesters. All participants were male, and their age ranges between 19-23, and they were enrolled in an undergraduate degree in English.

\section{Instruments}

The study seeks to explore reading ability levels, perceived strategy use, and self-reported proficiency in English. Thus, a reading test was used to determine reading ability, the Survey of Reading Strategies (SORS) was used to explore strategy perceived use, and a demographic questionnaire to collect participants' perceived proficiency.

The reading test used was an older version of the TOEFL reading section that consisted of a traditional five-passage format that varies in topics and difficulty. The test is valid and reliable as attested by the English Testing Services, the ETS. Further, the test is recognized as a valid and accurate indicator of testees' actual reading level by university admission requirements worldwide.

The survey of reading strategies was devised by Mokhtari and Sheorey (2002) to measure ESL students' awareness of reading strategies. The survey is divided into three major sections: Global Reading Strategies (GLOB), the Problem-solving Strategies (PROB), and the Support Reading Strategies (SUP). Each subarea consists of several strategies. The survey is scored on a 5-Likert scale where scale 1 is" I never or almost never do this," and scale 5 is "I always or almost always use this strategy" (Mokhtari \& Sheorey, 2002, p. 10).

A detailed scoring sheet was also devised by Mokhtari and Sheorey (2002) to help interpret the results. Each section was listed separately on the scoring sheet. The researcher would add the scores for each item and then divide the sum by the number of strategies, namely 13 for the GLOB, 8 for the PROB, and 9 fits the SUP. The participant who would score 3.5 and higher is considered a high strategy user, 2.5 to 3.4 is considered medium, and less than 2.5 is low. Then the total scores of the 30 strategies would be added and then averaged by 30 to get the general assessment of strategy use.

The global reading strategies section (GLOB) consists of thirteen strategies. They basically deal with prereading activities. For example, one of the strategies asks whether a reader had a premeditated goal for undertaking the reading task; whether they 
would bonder their general background knowledge about the topic at hand; whether they would take a general overview of the text and tried to know what it was about, its length, organization, pictures, tables, and other textual aids. Thus, this subscale is more about preparing the setting for the act of reading.

The second set of strategies is the problemsolving strategies (PROB). This set is comprised of eight strategies. They are localized, focused strategies dealing with the actual reading process. They help the reader overcome textual and comprehension difficulties as the reading text unfolds. For example, reading speed adjustment, rereading, and backtracking for comprehension are examples of problem-solving strategies.

The third section is the support strategies section (SUP). It consists of 9 strategies that deal with basic techniques that most readers use. For example, a reader might resort to using a dictionary, underlining keywords or ideas, highlighting texts, translating to one's native language to further grasp a concept, etc.

The reliability of the tool is well established in several previous studies (e.g., Alhaqbani \& Riazi, 2012; Alsheikh, 2009; Ghaith \& El-Sanyoura, 2019; Malcolm, 2009; Mokhtari \& Sheroey, 2002; Sheorey \& Baboczky, 2008, etc.). Yet to be sure, the reliability coefficient test for this study was conducted, and the Cronbach's Alpha was 0.857 for the SORS 30 items. Thus, the instrument is reliable for the present study.

The demographic questionnaire comprises basic information about participants, such as information on their name, age, past English learning experiences, and, most importantly, their self-reported level of English proficiency. Selfreported proficiency is the third aspect of this study. The participants were asked to rank themselves on a three-level scale: advanced, intermediate, or low.

\section{Procedure}

The researcher presented the project to prospective participants during class meetings. They were told that participation is optional. Most of the students enrolled were willing to join. The students were first given the TOEFL test. The assigned time was 60 minutes. Then they were allowed a 15-minute break, and then they were asked to complete the SORS in addition to the demographic questionnaire.

\section{Data Analysis}

Each participant was given an ID number, and then the TOEFL was corrected on the customary 30marks score of the reading section of the TOEFL. After that, the questionnaires were analyzed based on the SORS descriptors. Then the data were fed to SPSS 26 Program for statistical analysis. In answering the first question, reading strategies were put in general order based on the means of the 30 strategies. Then, to answer the second question, the participants' reading abilities were divided into three levels: high ability, medium ability, and low ability readers. Each level was associated with their respective order of strategies. Then t-test was conducted to see whether there is statistical significance between the high ability and the low ability groups to answer the third question. Then, to answer the remaining questions, correlation tests were conducted to explore possible significant associations between perceived use of strategies, self-reported proficiency, and actual reading abilities.

\section{FINDINGS}

To answer the first question, "How do EFL learners use reading strategies? In what order?" the participants' responses to the SORS were fed to SPSS 26, and the descriptive statistics yield a rank order of the reading strategies (see Table 1). The overall average of strategy use is 3.33 , which according to the SORS, is considered medium use for the entire scale. The pattern is High PROP (3.59), Medium GLOB (3.24), then Medium SUP (3.22).

As the table shows, the top 13 strategies yield a mean of 3.5 and above, which is considered high use according to the SORS descriptor. Three of them are GLOB (23\%), six PROB (46\%), and four SUP strategies $(30 \%)$. Thus, the problem-solving subset is the highest in the high strategy use.

Fifteen strategies ranking from 14 to 28 are strategies of medium use. The breakdown of these strategies is nine GLOB strategies $(60 \%)$, three PROB (20\%), and three SUP strategies (20\%). The two remaining strategies are classified as low use, one GLOB, and one SUP.

To answer the first part of the second question, "Does reading ability level affect the order of strategy use? In other words, would high ability readers choose a different order of strategies from the lower two levels?" the participants were assigned to one of three groups based on their performance: high, intermediate, and low ability readers. The rank order of the high ability group is shown in Table 2. The pattern of strategy use is High PROB (3.63), Medium GLOB (3.23), and then Medium SUP (2.95). The total strategy use is medium (3.25).

The high ability group reported high use of 15 strategies. They are as follows: seven PROB (47\%), five GLOBS (33\%), and three SUPs $(20 \%)$. As for the medium use, the group reported 12 strategies: eight GLOBs (67\%), three SUPs (25\%), and one PROB (8\%). And the low reported strategies were only three: two SUPs and one GLOB. 
Table 1

The Rank Order of Reading Strategies

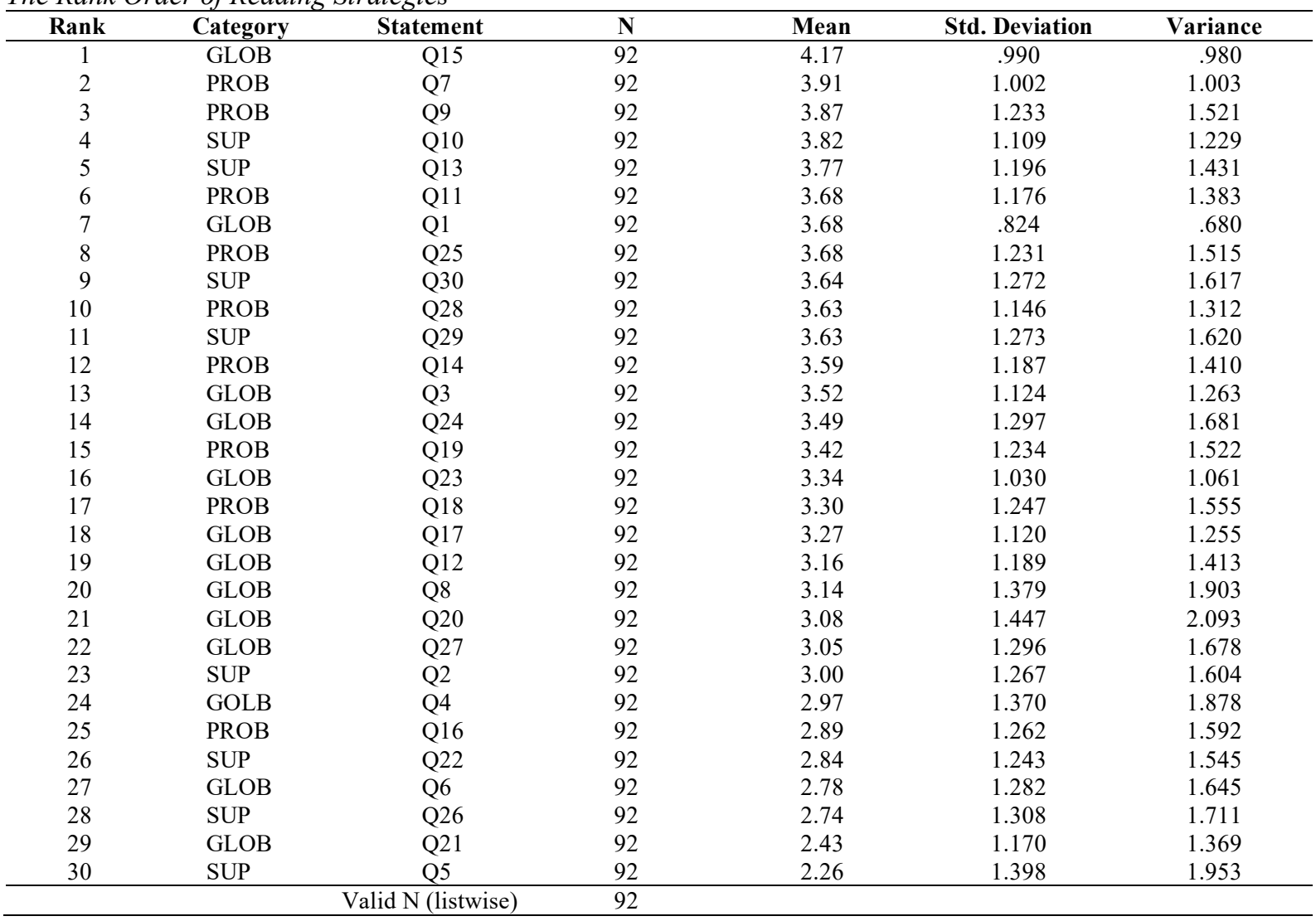

Table 2

High Reading Ability Strategy Order

\begin{tabular}{|c|c|c|c|c|c|c|}
\hline Rank & Category & Statement & $\mathbf{N}$ & Mean & Std. Deviation & Variance \\
\hline 1 & GLOB & Q3 & 12 & 4.17 & .718 & .515 \\
\hline 2 & GLOB & Q15 & 12 & 4.00 & .953 & .909 \\
\hline 3 & PROB & Q25 & 12 & 3.92 & 1.443 & 2.083 \\
\hline 4 & PROB & Q14 & 12 & 3.92 & .996 & .992 \\
\hline 5 & SUP & Q10 & 12 & 3.92 & 1.084 & 1.174 \\
\hline 6 & PROB & Q9 & 12 & 3.83 & 1.030 & 1.061 \\
\hline 7 & GLOB & Q17 & 12 & 3.67 & .985 & .970 \\
\hline 8 & PROB & Q11 & 12 & 3.67 & .985 & .970 \\
\hline 9 & PROB & Q19 & 12 & 3.58 & 1.379 & 1.902 \\
\hline 10 & SUP & Q13 & 12 & 3.58 & 1.443 & 2.083 \\
\hline 11 & PROB & Q7 & 12 & 3.58 & 1.084 & 1.174 \\
\hline 12 & PROB & Q28 & 12 & 3.58 & .900 & .811 \\
\hline 13 & SUP & Q18 & 12 & 3.50 & 1.314 & 1.727 \\
\hline 14 & GLOB & Q1 & 12 & 3.50 & .905 & .818 \\
\hline 15 & GLOB & Q20 & 12 & 3.50 & 1.382 & 1.909 \\
\hline 16 & GLOB & Q24 & 12 & 3.42 & 1.240 & 1.538 \\
\hline 17 & GLOB & Q23 & 12 & 3.33 & .888 & .788 \\
\hline 18 & GLOB & Q8 & 12 & 3.08 & 1.564 & 2.447 \\
\hline 19 & GLOB & Q12 & 12 & 3.00 & 1.044 & 1.091 \\
\hline 20 & GLOB & Q4 & 12 & 3.00 & 1.206 & 1.455 \\
\hline 21 & PROB & Q16 & 12 & 2.92 & 1.165 & 1.356 \\
\hline 22 & SUP & Q30 & 12 & 2.83 & 1.115 & 1.242 \\
\hline 23 & GLOB & Q29 & 12 & 2.75 & 1.422 & 2.023 \\
\hline 24 & SUP & Q26 & 12 & 2.67 & .985 & .970 \\
\hline 25 & SUP & Q22 & 12 & 2.67 & 1.073 & 1.152 \\
\hline 26 & GLOB & Q27 & 12 & 2.58 & 1.084 & 1.174 \\
\hline 27 & GLOB & Q21 & 12 & 2.50 & .674 & .455 \\
\hline 28 & SUP & Q2 & 12 & 2.33 & 1.073 & 1.152 \\
\hline 29 & SUP & Q5 & 12 & 2.33 & 1.557 & 2.424 \\
\hline \multirow[t]{2}{*}{30} & GLOB & Q6 & 12 & 2.25 & 1.138 & 1.295 \\
\hline & & Valid N (listwise) & 12 & & & \\
\hline
\end{tabular}


The intermediate reading ability level group reported the following strategy rank order. As table 3 shows, thirteen strategies high, fifteen medium, and two low. The top thirteen 3.5 and above are as follows: six PROBs $(46 \%)$, four SUPs $(30 \%)$, and three GLOBs $(23 \%)$. The fifteen medium strategies are nine GLOBs (60\%), four SUPs (27\%), and two PROB (13\%). As for the low one GLOB and one SUP. The general order is high PROB (3.61), medium SUP (3.26), then medium GLOB (3.21). The overall level is medium (3.33).

Table 3

Intermediate Reading Ability Order

\begin{tabular}{clccccc}
\hline Rank & Category & Statement & $\mathbf{N}$ & Mean & Std. Deviation & Variance \\
\hline 1 & GLOB & Q15 & 68 & 4.18 & .961 & .924 \\
2 & PROB & Q7 & 68 & 4.00 & .977 & .955 \\
3 & PROB & Q9 & 68 & 3.90 & 1.259 & 1.586 \\
4 & SUP & Q29 & 68 & 3.81 & 1.188 & 1.411 \\
5 & SUP & Q10 & 68 & 3.81 & 1.096 & 1.202 \\
6 & SUP & Q13 & 68 & 3.78 & 1.183 & 1.398 \\
7 & PROB & Q11 & 68 & 3.74 & 1.154 & 1.332 \\
8 & SUP & Q30 & 68 & 3.72 & 1.280 & 1.637 \\
9 & PROB & Q28 & 68 & 3.66 & 1.141 & 1.302 \\
10 & GLOB & Q1 & 68 & 3.65 & .806 & .650 \\
11 & PROB & Q25 & 68 & 3.62 & 1.172 & 1.374 \\
12 & PROB & Q14 & 68 & 3.56 & 1.214 & 1.474 \\
13 & GLOB & Q24 & 68 & 3.50 & 1.240 & 1.537 \\
14 & GLOB & Q3 & 68 & 3.44 & 1.111 & 1.235 \\
15 & PROB & Q19 & 68 & 3.41 & 1.225 & 1.500 \\
16 & GLOB & Q23 & 68 & 3.29 & 1.120 & 1.255 \\
17 & SUP & Q18 & 68 & 3.21 & 1.229 & 1.509 \\
18 & GLOB & Q17 & 68 & 3.15 & 1.123 & 1.262 \\
19 & GLOB & Q8 & 68 & 3.15 & 1.330 & 1.769 \\
20 & SUP & Q2 & 68 & 3.13 & 1.280 & 1.639 \\
21 & GLOB & Q12 & 68 & 3.13 & 1.233 & 1.520 \\
22 & GLOB & Q27 & 68 & 3.01 & 1.299 & 1.686 \\
23 & GLOB & Q4 & 68 & 2.99 & 1.419 & 2.015 \\
24 & PROB & Q16 & 68 & 2.97 & 1.293 & 1.671 \\
25 & GLOB & Q20 & 68 & 2.94 & 1.402 & 1.967 \\
26 & GLOB & Q6 & 68 & 2.93 & 1.285 & 1.651 \\
27 & SUP & Q22 & 68 & 2.93 & 1.285 & 1.651 \\
28 & SUP & Q26 & 68 & 2.71 & 1.316 & 1.733 \\
29 & GLOB & Q21 & 68 & 2.44 & 1.151 & 1.325 \\
30 & SUP & Q5 & 68 & 2.24 & 1.351 & 1.824 \\
\hline & & Valid N (listwise) & 68 & & &
\end{tabular}

The low ability reading group yielded the results that are showing in Table 4 . The sixteen high-use strategies, eleven medium, and three low. The breakdown of these levels are as follows: the sixteen high use are seven GLOBs (44\%), five SUPs (31\%), and four PROB (25\%). The eleven medium strategies are five GLOBs $(46 \%)$, three PROBs $(27 \%)$, and three SUPs $(27 \%)$. As for the low reported strategies, there were three: a PROB, a GLOB, and a SUP reading strategy $(33.33 \%$ each). The overall general pattern is medium PROB (3.43), medium GLOB (3.38), then medium SUP (3.29). The overall level is medium (3.36).

To answer the second part of the second question, "Is there statistical significance between the high ability and the low ability groups in terms of reported strategy use? independent t-test was conducted to see if there is a statistical significance between the two groups. The results show no statistical significance at the overall level of strategy use $p=0.06$, the PROB $p=0.339$, and SUP $p=0.213$ subscales. However, a statistical significance was found in the GLOB subscale were $(\mathrm{p}=0.01), \mathrm{p}<$ 0.05 . The low ability group used more global strategies (seven GLOBs high use, five mediums, and one low use) than the high-level group (five GLOBs high use, eight GLOBs medium, and one low use).

The first part of the third question was answered by conducting the Spearman's correlation test to see if there was a relationship between the perceived strategy use and the perceived language proficiency (see Table 5). The results yielded no significant associations between these two variables. Though beyond question asked, the researcher was intrigued to see whether there was another relevant relationship. Thus, another correlation test was conducted to explore a possible relationship between reading ability, strategy use, and the results yielded no significance either.

Further, to answer the second part of the third question, "Is there a relationship between reading 
ability as manifested in TOEFL scores and reading strategies?" A correlation test was conducted to see if any of the specific groups would yield any significant correlation, and the result still the same, no association between the strategy use and the reading ability among the three ability levels, as could be seen in Table 6 .

As for the last part of the third question, which reads," Does perceived reading proficiency correlate with reading ability? The question is meant to see if the students were over or underestimating their abilities. Since the data is large enough and ordinal, the Spearman's rank correlation coefficient test was conducted between these two variables, and the answers are shown in Table 7. The results show a strong relationship between the self-reported proficiency and actual reading test $p=0.00$, which is less than $p=0.05$. This suggests accurate awareness of students' abilities. The same test was conducted with actual TOEFL scores, and the same results were confirmed at this significance level.

Table 4

Low Reading Ability Order

\begin{tabular}{|c|c|c|c|c|c|c|}
\hline Rank & Category & Statement & $\mathbf{N}$ & Mean & Std. Deviation & Variance \\
\hline 1 & GLOB & Q15 & 12 & 4 & 4.33 & 1.231 \\
\hline 2 & GLOB & Q1 & 12 & 2 & 4.08 & .793 \\
\hline 3 & SUP & Q30 & 12 & 3 & 4.00 & 1.128 \\
\hline 4 & SUP & Q13 & 12 & 3 & 3.92 & 1.084 \\
\hline 5 & PROB & Q25 & 12 & 4 & 3.83 & 1.403 \\
\hline 6 & GLOB & Q27 & 12 & 4 & 3.75 & 1.288 \\
\hline 7 & SUP & Q10 & 12 & 4 & 3.75 & 1.288 \\
\hline 8 & PROB & Q9 & 12 & 4 & 3.75 & 1.357 \\
\hline 9 & PROB & Q7 & 12 & 3 & 3.75 & 1.055 \\
\hline 10 & SUP & Q18 & 12 & 4 & 3.67 & 1.303 \\
\hline 11 & GLOB & Q17 & 12 & 3 & 3.58 & 1.165 \\
\hline 12 & GLOB & Q23 & 12 & 1 & 3.58 & .515 \\
\hline 13 & GLOB & Q12 & 12 & 4 & 3.50 & 1.087 \\
\hline 14 & SUP & Q29 & 12 & 3 & 3.50 & 1.314 \\
\hline 15 & PROB & Q28 & 12 & 4 & 3.50 & 1.446 \\
\hline 16 & GLOB & Q24 & 12 & 4 & 3.50 & 1.732 \\
\hline 17 & GLOB & Q20 & 12 & 4 & 3.42 & 1.730 \\
\hline 18 & PROB & Q14 & 12 & 3 & 3.42 & 1.240 \\
\hline 19 & PROB & Q11 & 12 & 4 & 3.42 & 1.505 \\
\hline 20 & PROB & Q19 & 12 & 4 & 3.33 & 1.231 \\
\hline 21 & GLOB & Q3 & 12 & 4 & 3.33 & 1.371 \\
\hline 22 & GLOB & Q8 & 12 & 4 & 3.17 & 1.586 \\
\hline 23 & SUP & Q26 & 12 & 4 & 3.00 & 1.595 \\
\hline 24 & SUP & Q2 & 12 & 4 & 2.92 & 1.240 \\
\hline 25 & GLOB & Q4 & 12 & 4 & 2.83 & 1.337 \\
\hline 26 & SUP & Q22 & 12 & 3 & 2.50 & 1.168 \\
\hline 27 & GLOB & Q6 & 12 & 4 & 2.50 & 1.314 \\
\hline 28 & PROB & Q16 & 12 & 3 & 2.42 & 1.165 \\
\hline 29 & SUP & Q5 & 12 & 4 & 2.33 & 1.614 \\
\hline \multirow[t]{2}{*}{30} & GLOB & Q21 & 12 & 4 & 2.33 & 1.670 \\
\hline & & Valid N (listwise) & 12 & & & \\
\hline
\end{tabular}

Table 5

Spearman's Correlation Between Self-Reported Proficiency and Reading Strategies

\begin{tabular}{llcccccc} 
& & & Self-report & GLOB & PROB & SUP & Overall \\
\cline { 3 - 8 } Spearman's Rho & Self-Reported & Correlation Coefficient & 1.000 & .026 & -.168 & -.076 & -.073 \\
& Proficiency & Sig. (2-tailed) &. & .806 & .110 & .472 & .487 \\
& & $\mathrm{~N}$ & 92 & 92 & 92 & 92 & 92 \\
\hline
\end{tabular}

Table 6

Person's Correlation between TOEFL Score and Reading Strategies

\begin{tabular}{|c|c|c|c|c|c|}
\hline & & $\begin{array}{c}\text { Global } \\
\text { Strategies }\end{array}$ & $\begin{array}{c}\text { Problem Solving } \\
\text { Strategies }\end{array}$ & $\begin{array}{c}\text { Support } \\
\text { Strategies }\end{array}$ & Overall Strategy \\
\hline \multirow{3}{*}{$\begin{array}{l}\text { High } \\
\text { TOEFL Score }\end{array}$} & Correlation & .194 & .005 & -.172 & -.027 \\
\hline & Sig. (2-tailed) & .546 & .988 & .592 & .933 \\
\hline & $\mathrm{N}$ & 12 & 12 & 12 & 12 \\
\hline \multirow{3}{*}{$\begin{array}{l}\text { Intermediate } \\
\text { TOEFL Score }\end{array}$} & Correlation & .118 & -.010 & .046 & .068 \\
\hline & Sig. (2-tailed) & .337 & .935 & .707 & .581 \\
\hline & $\mathrm{N}$ & 68 & 68 & 68 & 68 \\
\hline \multirow{3}{*}{$\begin{array}{l}\text { Low } \\
\text { TOEFL Score }\end{array}$} & Correlation & -.358 & -.079 & -.492 & -.368 \\
\hline & Sig. (2-tailed) & .254 & .806 & .105 & .240 \\
\hline & $\mathrm{N}$ & 12 & 12 & 12 & 12 \\
\hline
\end{tabular}


Table 7

Correlation between Reading Ability and Self-Reported Proficiency

\begin{tabular}{|c|c|c|c|c|}
\hline & & & Reading Ability & Self. Reported Proficiency \\
\hline Spearman's Rho & Reading Ability & $\begin{array}{c}\text { Correlation Coefficient } \\
\text { Sig }\end{array}$ & 1.000 & $\begin{array}{c}.392^{* *} \\
000\end{array}$ \\
\hline & & $\mathrm{N}$ & 92 & 92 \\
\hline
\end{tabular}

**. Correlation is significant at the 0.01 level (2-tailed).

\section{DISCUSSION}

The results of this study lend themselves to vast interpretations in terms of the three subscales of reading strategies, their order, the intensity of use, and their relationship to self-reported proficiency and various reading abilities. The first major finding is that different levels of reading abilities have different order and level of strategy use. The general pattern for the entire sample was high PROB, medium GLOB, and medium SUP with overall medium use. This pattern conforms to the high ability group and low ability group patterns. However, it is different from the pattern of the intermediate reading ability group, which was high PROB, medium SUP and then medium GLOB. The reported higher use of the SUP strategies could be interpreted because of the need for comprehension considering the limited vocabulary of the learners. The high use of SUP strategies reported were all pertinent to translation and using dictionaries or underlining keywords (see Table 4 above). This supports the findings that were asserted by HsuehChao and Nation (2000), who contend that readers need to know at least $98 \%$ of the words to fully comprehend a text in a foreign language.

Further, the intermediate ability group's pattern was found similar to the order found in Ghaith and El-Sanyoura (2019); Ghwela et al. (2017); Zuledwi et al. (2018), whose participants were also intermediate ability level. However, the same order was not found in the high ability group whose rank order left the SUP strategies to be the least. Thus, as the ability to read goes higher, readers seem to lessen their reliance on SUP strategies with a stronger emphasis on the GLOB strategies instead. Thus, the order becomes higher PROB, medium GLOB, and medium SUP. As readers become more proficient, they employ more PROB strategies, as was confirmed by Alsheikh (2009) and Tsai et al. (2010), who found that PROB strategies are used more by high proficiency readers. GLOB strategies are also used more as reading ability rises to overcome mainly vocabulary difficulties, a finding that is supported by Zhang (2001).

The low ability group reported similar order of strategy use as the high ability, but the intensity of use was lesser. The use of strategies was medium across the board. This result conforms to Meniado's (2016) study, where the first-year college student participants (low/beginner level) reported medium use of the three subscales. Further, the low ability group was found more reliant (at a statistically significant level) on GLOB strategies than the high ability group. This is to compensate for lower decoding/processing abilities. In addition, the lower ability learners suffer from other weaknesses in terms of vocabulary and general language proficiency. The reported GLOB strategies (see Table 5) are more concerned with understanding the text without having to translate much. I found that readers at this level are trying to figure out the meaning from the reading aids and clues. As they move up towards the intermediate level, they employ more SUP strategies and intensify their use of PROB strategies. The finding supports Phakiti (2003), who asserted that high and low ability readers differ in using metacognitive reading strategies.

The correlation tests that were done in this study found a strong association between the reported proficiency and the reading abilities. This means that students were accurate when they rated themselves. However, their levels, whether they were reported or scored in a standardized test, did not correlate with reading strategies in all three subscales as reported in Table 7. It seems that the readers in this study were not as accurate when they reported their levels of strategy use. This finding is not very uncommon in the literature. Özkan Gürses and Bouvet (2016), for example, did not find a significant correlation between reading comprehension and reading strategies in both subgroups of Turkish and Australian participants. Similarly, Alsamadani (2009) and Mónos(2005) did not find a significant correlation between reading strategies and comprehension as measured by test scores. Mónos explained the lack of association between reading ability and perceived strategy use to test difficulty that might justify poor students' performance despite the reported high use of reading strategies.

For the present study, there might be other variables that caused the absence of a correlation between reading ability and perceived strategy use in the present study. One possibility is the excessive strategy instruction that students in this study were receiving. In reading classes like the ones that the participants of this study take, students receive intensive instruction in reading strategies. It is my contention that the participants became more aware of the strategies, but they did not have time to internalize, operationalize, and automatize this knowledge. Further, it has been contended that 
learners might perceive reading strategies, but they may not necessarily transform perception into actual use while reading (Mokhtari \& Sheorey., 2002).

\section{CONCLUSION}

A central goal of reading instruction/education is to assist low-level students in improving their reading abilities to match the high ability readers. Because most of nowadays reading classes teach strategies to some extent, there is a shred of mounting evidence that explicit strategy instruction is the way to go. Thus, we may draw few conclusions based on the findings and observations from this study. First, this study confirmed that students at different levels of reading proficiency reported different use of reading strategies. The difference is twofold: order and intensity. The intermediate level showed different order from both the high level and the low level. As for the intensity, the low level reported medium use of strategies in all three subscales in the SORS.

An implication of this finding would be a better understanding of how learners progress through ability levels. Teachers can use this to assist their lower ability students in using more supporting strategies to get them better understand reading texts and eventually move to the intermediate level. They also need to train them to elevate their perception of the problem-solving strategies to match those in the intermediate level.

Second, the lower-level participants rely on the global strategies to compensate for other critical skills, like automatic decoding of the written word, limited vocabulary, and ability to guess word meaning from context. It is crucial for teachers and students alike to work on building up vocabulary and practice more reading using other strategies in the PROB subscale.

Third, the intermediate ability level has its own peculiarities. Participants in this level employ more SUP strategies, particularly translation and dictionary use. This highlights their need for comprehension compared to the lower level. Though using SUP strategies as such is commendable, it should not be at the expense of time and effort invested in any given reading. Having to stop at every other word to look it up would be impractical in many situations, such as exams. So, teachers should assist their students in using these SUP strategies sparingly and employ more PROB and GLOB strategies instead.

Finally, curriculum designers should keep themselves on the lookout for studies like the present one. There might be some helpful ideas that could facilitate teaching and learning of reading in a foreign language. One suggestion is to present reading strategies in a way that is gradual and mirrors the ability level requirements as found in this study.
As alluded to in the introduction, the results reported in this study might not necessarily apply to other learners from different L1 backgrounds, as other learners might have their own preferences.

\section{ACKNOWLEDGEMENTS}

I would like to thank King Khalid University, Saudi Arabia, for granting me a sabbatical leave to have time to conduct the research reported here. I also would like to thank my students who participated in this effort with open hearts and minds.

\section{REFERENCES}

Abbott, M. (2006). ESL reading strategies: Differences in Arabic and Mandarin speaker test performance. Language Learning, 56(4), 633-670. http://dx.doi.org/10.1111/j.14679922.2006.00391.x

Alhaqbani, A., \& Riazi, M. (2012). Metacognitive awareness of reading strategy use in Arabic as a second language. Reading in a foreign language, 24(2), 231-255.

Alsamadani, H. A. (2009). The relationship between Saudi EFL college-level students' use of reading strategies and their EFL reading comprehension [Doctoral dissertation]. Retrieved https://etd.ohiolink.edu/rws_etd/document/get/ ohiou $1224685570 /$ inline

Alsheikh, N. (2009). The strategic reading of Arabic native speakers in English: An examination of the metacognitive reading strategies used by Arabic native speakers when reading academic texts in Arabic and English. VDM Verlag Publisher.

Baker, L. \& Brown, A. L. (1984). Metacognitive skills and reading. In P. D. Pearson, ed., Handbook of Reading Research, Vol. 1 (pp. 353-394). Longman.

Bang, H. J. \& Zhao, C. G. (2007). Reading strategies used by advanced Korean and Chinese ESL graduate students: A case study. The Reading Matrix, 7(1), 30-50.

Block, E. (1986). The comprehension strategies of second language readers. TESOL Quarterly, 20(3), 463-494. https://doi.org/10.2307/3586295

Carrell, P. L. (1985). Facilitating ESL reading by teaching text structure. TESOL Quarterly, 727-752. https://doi.org/10.2307/3586673

Carrell, P. L. (1989). Metacognitive awareness and second language reading. Modern Language Journal, 73, 121-134. https://doi.org/10.1111/j.15404781.1989.tb02534.x

Carrell, P. L. (1998). Can reading strategies be successfully taught? Australian Review of 
Applied Linguistics, 21(1), 1-20.

https://doi.org/10.1075/aral.21.1.01car

Clarke, M. (1979). Reading in Spanish and English: Evidence from adult ESL students. Language Learning, 29(1), 121-147. https://doi.org/10.1111/j.14671770.1979.tb01055.x

Ghaith, G., \& El-Sanyoura, H. (2019). Reading comprehension: The mediating role of metacognitive strategies. Reading in a Foreign Language, 31, 19-43.

Ghwela, M., Rosniah, M., \& Noorizah, M. N. (2017). Metacognitive reading strategies of EFL Libyan university learners. International Journal of Social Sciences and Humanities Research, 5, 332-339.

Goodman, K. (1967). Reading: A psycholinguistic guessing game. Journal of the Reading Specialist, 6, 126-135. http://dx.doi.org/10.1080/19388076709556976

Gough, P. B. (1972). One second of learning. In J. Kavanagh \& I. Matting (Eds.), Language by ear and by eye (pp. 331-358). Mss: MIT Press.

He, T. (2008). Reading for different goals: The interplay of the EFL college students' multiple goals, reading strategy use and reading comprehension. Journal of research in reading, 31(2), 224-242.

https://doi.org/10.1111/j.14679817.2007.00355.x

Hsueh-Chao, M. H., \& Nation, P. (2000). Unknown vocabulary density and reading comprehension. Reading in a Foreign Language, 13, 403-430. https://doi.org/10.26686/wgtn.12560354.v1

Lee-Thompson, L-C. (2008). An investigation of reading strategies applied by American learners of Chinese as a foreign language. Foreign Language Annuals, 14, 702-721. https://doi.org/10.1111/j.19449720.2008.tb03326.x

Madhumathi, P., \& Ghosh, A. (2012). Awareness of reading strategy use of Indian ESL students and the relationship with reading comprehension achievement. English Language Teaching, 5(12), 131-140. http://dx.doi.org/10.5539/elt.v5n12p131

Malcolm, D. (2009). Reading Strategy Awareness of Arabic-Speaking Medical Students Studying in English. System, 37, 640-651. https://doi.org/10.1016/j.system.2009.09.008

Meniado, J. (2016). Metacognitive reading strategies, motivation, and reading comprehension performance of Saudi EFL students. English Language Teaching, 9(3), 117. https://doi.org/10.5539/elt.v9n3p117

Mokhtari, K., \& Sheorey, R. (2002). Measuring ESL students' awareness of reading strategies. Journal of Developmental Education, 25(3), 210.
Mónos, K. (2005). A study of the English reading strategies of Hungarian university students with implications for reading instruction in an academic context. Malaysian Journal of ELT Research, Inaugural Volume, 1-23. Retrieved from

http://www.melta.org.my/Doc/MonosK_Eng_r eading_strategies.pdf

Özkan Gürses, M., \& Bouvet, E. (2016). Investigating reading comprehension and learning styles in relation to reading strategies in L2. Reading in a Foreign Language, 28(1), 20-42.

Pammu, A., Amir, Z., \& Maasum, T. (2014). Metacognitive reading strategies of less proficient tertiary learners: A case study of EFL learners at a public university in Makassar, Indonesia. Procedia, 118, 357-364. http://dx.doi.org/10.1016/j.sbspro.2014.02.049

Phakiti, A. (2003). A closer look at the relationship of cognitive and metacognitive strategy use to EFL reading achievement test performance. Language Testing, 20(1), 26-56. https://doi.org/10.1191/02655322031t243oa

Sheorey, R., \& Baboczky, E. S. (2008). Metacognitive awareness of reading strategies among Hungarian college students. In K. Mokhtari \& R. Sheorey (Eds.), Reading strategies of first- and secondlanguage learners: See how they read (pp. 161-173). Christopher-Gordon Publishers.

Sheorey, R., \& Mokhtari, K. (2001). Differences in the metacognitive awareness of reading. System, 29, 431-449. https://doi.org/10.1016/S0346251X(01)00039-2

Stanovich, K. (1980). Towards the interactivecompensatory model of individual differences in the development of reading fluency. Reading Research Quarterly, 16, 32-71. http://dx.doi.org/10.2307/747348

Tavakoli, H. (2014). The effect of explicit metacognitive strategy awareness in reading comprehension: The case of Iranian university EFL students. The Reading Matrix, 14(2), 314-336. https://doi.org/10.30827/digibug.53893

Tsai, Y., Ernst, C., \& Talley, P. (2010). L1 and L2 strategy use in reading comprehension of Chines EFL readers. Reading Psychology, 31(1), 1-29. https://doi.org/10.1080/02702710802412081

Zhang, L. (2001). Awareness in reading: EFL students' metacognitive knowledge of reading strategies to an acquisition-poor environment. Language Awareness, 10(4), 268-288. https://doi.org/10.1080/09658410108667039

Zhou, X. \& Zhao, Y. (2014). A comparative study of reading strategies used by Chinese English 
majors. English Language Teaching, 7(3), 1318. https://doi.org/10.5539/elt.v7n3p13

Zuledwi, W., Ratmanida, R., \& Marlina, L. (2018). The relationship of students' metacognitive reading strategies awareness and reading comprehension: The case of the sixth semester students of English department, University of Negeri Pandang, (UND). Journal of English Language Teaching, 7, 399-413.

https://doi.org/10.24036/jelt.v7i3.100314 